\title{
THE FEBRUARY MEETING OF THE AMERICAN MATHEMATICAL SOCIETY.
}

The two hundred fourteenth regular meeting of the Society was held at Columbia University on Saturday, February 26, extending through the usual morning and afternoon sessions. The attendance included the following thirty-five members:

Professor J. W. Alexander, Mr. D. R. Belcher, Professor A. A. Bennett, Professor E. W. Brown, Dr. G. A. Campbell, Dr. Tobias Dantzig, Dr. Jesse Douglas, Professor L. P. Eisenhart, Professor H. B. Fine, Mr. R. M. Foster, Mr. Philip Franklin, Dr. T. C. Fry, Professor O. E. Glenn, Dr. T. H. Gronwall, Dr. C. C. Grove, Dr. A. A. Himwich, Professor E. V. Huntington, Mr. S. A. Joffe, Professor Edward Kasner, Professor O. D. Kellogg, Dr. E. A. T. Kircher, Dr. K. W. Lamson, Mr. Harry Langman, Professor G. W. Mullins, Professor F. W. Owens, Dr. E. L. Post, Professor H. W. Reddick, Professor L. W. Reid, Professor R. G. D. Richardson, Dr. J. F. Ritt, Dr. Caroline E. Seely, Professor L. P. Siceloff, Miss Louise E. C. Stuerm, Professor H. D. Thompson, Professor E. B. Wilson.

Ex-President H. B. Fine occupied the chair. The Council announced the election of the following one hundred fourteen persons to membership in the Society:

Professor Orrin Wilson Albert, Grinnell College;

Professor David Robert Allen, University of Utah;

Mr. Elbert Frank Allen, University of Missouri;

Professor Charles Lincoln Arnold, Ohio State University;

Miss Mary Caroline Ball, Northwestern University;

Professor Wightman Samuel Beckwith, Ohio Northern University;

Mr. William Noël Birchby, California Institute of Technology;

Dr. Edwin Mortimer Blake, Brooklyn, N. Y.;

Miss Rachel Blodgett, Harvard University;

Professor Rosser Daniel Bohannan, Ohio State University;

Professor John David Bond, Agricultural and Mechanical College of Texas;

Mr. Frederick William Borgward, Syracuse University;

Dr. Henry Roy Brahana, University of Illinois;

Professor William Mayo Brodie, Virginia Polytechnic Institute;

Mr. Bancroft Huntington Brown, Harvard University;

Professor Lillian Olive Brown, Hood College;

Professor Frank Newton Bryant, Syracuse Unniversity;

Miss Minnie Wilford Caldwell, Hardin College;

Miss Evelyn Teresa Carroll, Wells College; 
Mr. Ming-Cheng Chow, University of Cincinnati;

Mr. Oliver Charles Collins, University of Nebraska;

Professor Allan Ray Congdon, University of Nebraska;

Miss Mary Lucile Copenhover, University of Oregon;

Miss Julia Dale, University of Missouri;

Mr. Harold Thayer Davis, University of Wisconsin;

Miss Alice Crowell Dean, Rice Institute;

Professor Dewey Stevens Dearman, Millsaps Academy;

Professor Alexander Dillingham, United States Naval Academy;

Professor Eleanor Catherine Doak, Mount Holyoke College;

Mr. Theodore Doll, Northwestern University;

Rev. Joseph Nicholas Donohue, Notre Dame University;

Mr. Finis Omer Duncan, University of Missouri;

Miss Edna May Feltges, University of Wisconsin;

Mr. Malcolm Cecil Foster, Yale University;

Mr. Ronald Martin Foster, American Telephone and Telegraph Company;

Mr. Percy Austin Fraleigh, Cornell University;

Mr. Bennington Pearson Gill, College of the City of New York;

Mr. Rutherford Erwin Gleason, State University of Iowa;

Miss Neoma Lillian Goldsberry, University of Missouri;

Professor Cornelius Gouwens, Iowa State College;

Professor Harry Emil Gudheim, Virginia Polytechnic Institute;

Professor Truman Leigh Hamlin, Clarkson College;

Mr. Robert William Hartley, University of Pennsylvania;

Miss Camilla Hayden, University of Wisconsin;

Dr. Henry Benjamin Hedrick, United States Army Ordnance;

Miss Gertrude Anne Herr, Iowa State College;

Dr. Carl Einar Hille, University of Stockholm;

Professor Allan Wilson Hobbs, University of North Carolina;

Miss Clarice Sarah Hobensack, Ohio State University;

Miss Helma Lou Holmes, University of Texas;

Professor Alfred Hume, University of Mississippi;

Mr. William Anderson Hutcheson, Mutual Life Insurance Company;

Mr. Mark Hoyt Ingraham, University of Wisconsin;

Miss Margaret Eloise Jones, Ohio State University;

Professor Frederick Albert Lewis, University of Alabama;

Dr. Peysah Leyzerah, Lehigh University;

Professor Louis Lindsey, Syracuse University;

Mr. Joe Burton Linker, University of North Carolina;

Mr. Ralph Alden Loring, Dartmouth College;

Mr. Harold Marshall Lufkin, Cornell University;

Professor Edward Hiram McAlister, University of Oregon;

Miss Mary Bell McMillan, Wisconsin State Normal School, River Falls;

Mr. Israel Maizlish, Reed College;

Mr. Edward Lawrence Milne, Lake Forest Academy;

Mr. Thessalon Herbert Milne, University of Alberta;

Mr. Gordon Richmond Mirick, University of Rochester;

Mr. Allen Guy Montgomery, University of 'West Virginia;

Mr. David Sherman Morse, Cornell University;

Mr. Ray Dickinson Murphy, Equitable Life Assurance Society;

Dr. Almar Naess, Naval Academy of Norway;

Dr. Jason John Nassau, Syracuse University;

Mr. Charles Edward Norwood, United States Army Ordnance;

Professor John Hutcheson Ogburn, Lehigh University;

Professor Earnest Jackson Oglesby, New York University;

Mr. Jesse Otto Osborn, Pennsylvania State College;

Mr. Leroy Elden Peabody, Yale University;

Miss Elsie Marie Plapp, UUniversity of Wisconsin; 
Mr. Hillel Poritsky, Cornell University;

Miss Jessie Grace Quigley, University of Missouri;

Mr. Ottis Howard Rechard, University of Wisconsin;

Professor Jacob Charles Rietz, Ohio State University;

Professor Lulu Runge, University of Nebraska;

Mr. Howard Conway Shaub, Dartmouth College;

Mr. Charles Robert Sherer, University of Nebraska;

Professor Thomas McNider Simpson, Jr., Randolph-Macon College;

Miss Helen Florene Smith, Iowa State College;

Professor Merlin Grant Smith, Greenville College;

Mr. Marvin Reinhard Solt, Lehigh University;

Professor Charles Stillman Sperry, University of Colorado;

Mr. Eugene Stephens, Washington University;

Mrs. Elizabeth Easton Stickney, University of Illinois;

Miss Louise Elizabeth Cathrine Stuerm, American Telephone and Telegraph Company;

Professor Mary Clegg Suffa, Elmira College;

Mr. Frank Elmer Swift, Notre Dame University ;

Mr. James Henry Taylor, University of Nebraska;

Mr. Van B. Teach, Ohio State University;

Mr. Joseph Miller Thomas, University of Pennsylvania;

Professor Perley Lenwood Thorne, New York University;

Professor Joseph Ellis Trevor, Cornell University;

Professor Joseph Henry Tudor, Pennsylvania State College;

Professor Horace Scudder Uhler, Yale University;

Professor Harry Clark Van Buskirk, California Institute of Technology;

Mr. Charles Conroy Wagner, Pennsylvania State College;

Mr. Lewis Edes Ward, Harvard University;

Professor Emery Ernest Watson, Iowa State College for Teachers;

Professor Warren Weaver, University of Wisconsin;

Professor Ross Albert Wells, Michigan State Normal College;

Mr. Karl Leland Wildes, Massachusetts Institute of Technology;

Professor Robert Daniel Williams, Ohio State University;

Professor Charles Owen Williamson, College of Wooster;

Professor Harold Albert Wilson, Rice Institute;

Mr. Frederick Wood, University of Wisconsin;

Dr. Roscoe Woods, State University of Iowa;

Miss Jessica May Young, Washington University.

Twenty-four applications for membership in the Society were received.

The Council voted to accept the invitation extended by the American Association for the Advancement of Science to affiliate with it. Professor E. B. Van Vleck was appointed a representative of the Society in the division of physical sciences of the National Research Council, as successor to Professor H. S. White, whose term will soon expire.

The final report from Professor E. R. Hedrick, as chairman of the Committee on membership and sales, was received, and the committee was discharged at its own request, with the thanks of the Council for its notable services at this critical time. In all one hundred thirty-two applications for membership and seventy-seven subscriptions to the Transactrons for the current year have been received through this committee. 
[May,

Questions of policy were raised concerning dues for foreign members, concerning choice between Bulletin and TransACTIONS in the case of foreign members, concerning sales and exchanges of publications with foreign societies and libraries, and concerning individual or concerted efforts to aid foreign journals. It was voted to authorize the President to appoint a committee to consider these and related questions.

The secretary was requested to write on behalf of the Council a letter of felicitation to Professor Magnus Gösta Mittag-Leffler on the occasion of the seventy-fifth anniversary of his birth, March 16, 1921.

A letter from Professor F. N. Cole was read to the Council, donating to the Society the sum which accompanied the testimonial tendered him at the preceding meeting of the Society in recognition of his very distinguished services. It was voted that the Council accept the gift and extend to Professor Cole its heartiest appreciation of his generosity; it was further voted that this fund shall constitute and be designated as the Cole Fund, and the President was requested to appoint a committee to consider the use to which the income can best be devoted. The Council approved the suggestion that the present volume of the Bulletin be inscribed to Professor Cole.

The papers read at the February meeting are stated below. Those of Mr. Rice, Professor Glenn, Professor Moore, Dr. Zeldin, and Miss Mullikin, and the second paper of Dr. Ritt, were read by title.

1. Mr. L. H. Rice: Coefficient of the general term in the expansion of a product of polynomials.

The writer shows, first, that in the expansion of the product $\left(a_{1}+a_{2}+\cdots+a_{m}\right)\left(a_{2}+\cdots+a_{m}\right) \cdots\left(a_{m-1}+a_{m}\right) a_{m}$ the coefficient of the general term $A a_{a_{1}}^{\beta_{1}} a_{a_{2}}^{\beta_{2}} \cdots a_{a_{f-1}}^{\beta_{f-1}} a_{m}^{\beta_{f}}$, where $\alpha_{1}<\alpha_{2}<\cdots<m$, is:

$$
\begin{array}{r}
A=\left(\begin{array}{c}
\alpha_{1} \\
\beta_{1}
\end{array}\right)\left(\begin{array}{c}
\alpha_{2}-\beta_{1} \\
\beta_{2}
\end{array}\right)\left(\begin{array}{c}
\alpha_{3}-\beta_{2}-\beta_{1} \\
\beta_{3}
\end{array}\right) \\
\quad \ldots\left(\begin{array}{c}
\alpha_{f-1}-\beta_{f-2}-\cdots-\beta_{1} \\
\beta_{f-1}
\end{array}\right) .
\end{array}
$$

More generally, in the expansion of the product 


$$
\begin{aligned}
\left(a_{t_{1}}+a_{t_{1}+1}+\cdots+a_{n}\right)\left(a_{t_{2}}+a_{t_{2}+1}+\cdots+a_{n}\right) & \\
& \cdots\left(a_{t_{m}}+a_{t_{m}+1}+\cdots+a_{n}\right)
\end{aligned}
$$

the coefficient of the general term $B a_{a_{1}}^{\beta_{1}} a_{a_{2}}^{\beta_{2}} \cdots a_{a_{f}}^{\beta_{f}}$, where $\alpha_{1}<\alpha_{2}<\cdots<\alpha_{f}$, is

$$
\begin{array}{r}
B=\left(\begin{array}{c}
\alpha_{1}{ }^{\prime} \\
\beta_{1}
\end{array}\right)\left(\begin{array}{c}
\alpha_{2}{ }^{\prime}-\beta_{1} \\
\beta_{2}
\end{array}\right)\left(\begin{array}{c}
\alpha_{3}{ }^{\prime}-\beta_{2}-\beta_{1} \\
\beta_{3}
\end{array}\right) \\
\ldots\left(\begin{array}{c}
\alpha_{f-1}^{\prime}-\beta_{f-2}-\cdots-\beta_{1} \\
\beta_{f-1}
\end{array}\right),
\end{array}
$$

where $\alpha_{j}{ }^{\prime}$ is the number of $\alpha_{j}^{\prime}$ 's in the factors of the given product.

2. Professor E. V. Huntington: The mathematical theory of proportional representation, with a substitute for least squares.

The author shows that the new method of apportionment which he presented at the December meeting may be based on the following categorical set of postulates (in which $A$, $B, C, \cdots$ are the populations of the states, and $a, b, c, \cdots$ the number of representatives assigned to each): I. For the case of two states, the ratio between $A / a$ and $B / b$ (or $a / A$ and $b / B$; or $A / B$ and $a / b$; or $B / A$ and $b / a$ ) should be as near unity as possible. II. No pair of states should be capable of being improved by a transfer of representatives within that pair.

3. Professor F. W. Owens: On the apportionment of representatives.

This paper compares various used or proposed methods of apportionment, pointing out what might be considered as advantages and disadvantages, with illustrative examples. It is also shown that a justification of the method of major fractions may be found in a form of least squares. Suggestions are also offered as to special treatment of the first representative from each state.

4. Professor Arnold Emch: On the polar equation of algebraic curves.

The author studies the transformation

(1) $\sigma x_{1}{ }^{\prime}=x_{2}\left(x_{3}{ }^{2}-x_{1}{ }^{2}\right), \quad \sigma x_{2}{ }^{\prime}=2 x_{1} x_{2} x_{3}, \quad \sigma x_{3}{ }^{\prime}=\left(x_{1}{ }^{2}+x_{3}{ }^{2}\right) x_{3}$ between two planes $\left(x^{\prime}\right)$ and $(x)$, which occurs in the change 
from polar to cartesian coordinates. If we set $x_{1} / x_{3}=t$ $=\tan (\theta / 2), \quad x_{2} / x_{3}=\rho, x_{1}{ }^{\prime} / x_{3}{ }^{\prime}=x, x_{2}{ }^{\prime} / x_{3}{ }^{\prime}=y$, the polar equation of an algebraic curve $F(\rho, \cos \theta, \sin \theta)=0$ may be written in the form $\phi^{*}(t, \rho)=0$, or $\phi\left(x_{1}, x_{2}, x_{3}\right)=0$. By means of the transformation (1) the equation $\phi=0$ is transformed into the projective equation $f\left(x_{1}{ }^{\prime}, x_{2}{ }^{\prime}, x_{3}{ }^{\prime}\right)=0$ of the algebraic curve $F=0$. Interpreting $\phi$ in the projective plane $(x)$, we may speak of the $\phi$-curve. The fundamental points of the transformation (1) are the double point $(0,1,0)$, and the single points $(1,0,0),(1,0, i),(1,0,-i)$.

It is shown that to the polar equation in the $\phi$-form of order $n$ and deficiency $p$, in a general position, i.e., independent of the fundamental points, corresponds an algebraic curve $f$ of order $3 n$ and the same deficiency. The singularities of $f$ are discussed in detail and are described in full.

Reductions in the order of $f$ and in its multiple points due to the passage of $\phi$ through the fundamental points or the arrangement of the points of $\phi$ in couples are also considered. The method outlined in this paper is useful in studying the singularities of an algebraic curve from its polar equation.

5. Professor O. E. Glenn: Generalization of the concept of invariancy derived from a type of correspondence between functional domains. Second proof of the finiteness of formal binary concomitants modulo $p$.

Two functional domains $D, Q$ may be so related that, by a transformation, there exists, for functions $\varphi$ of $D$, an invariant relation $\varphi^{\prime}=r \varphi$ while a correspondence $\varphi \sim \omega$ with functions $\omega$ of $Q$ holds which implies also $\omega^{\prime}=s \omega$. There follows $\varphi=q \omega$ where $\varphi$, in some particular cases, is the same function of its arguments as is $\omega$, and in other cases a different function. Combining the above with a theory of invariant elements, the author obtains a proof of the finiteness of formal modular concomitant systems in better alignment with formal methods than his proof given at the December (1920) meeting.

6. Professor R. L. Moore: Concerning the sum of a countable number of closed point sets.

In the Tôhoku Mathematical Journal, vol. 13, June, 1918, pp. 300-303, Sierpinski shows that, in a space of $m$ dimensions, if the sum $M$ of a countable number of mutually exclusive closed point sets is closed and bounded, then $M$ is 
not connected. He points out that if the stipulation that $M$ be bounded is removed the thus modified proposition holds for $m=1$ but not for $m=3$. He raises the question whether it holds for $m=2$. Professor Moore answers this question by showing the existence of an unbounded closed and connected plane point set which is the sum of a countable number of mutually exclusive closed point sets. He shows, in addition, that Sierpinski's theorem remains true for every $m$ if the stipulation that $M$ be bounded is retained but the stipulation that $M$ be closed is replaced by the stipulation that if there be any limit point of $M$ that does not belong to $M$ then the set of all such limit points be closed.

7. Dr. S. D. Zeldin: On the simplification of the structure of finite continuous groups with more than one two-parameter invariant subgroup.

In this paper the author shows how the structure of a group of order $r+2 k$ with $k>1$ two-parameter invariant subgroups can be simplified if its meroedrically isomorphic group of order $r$ has one invariant spread. He shows that the adjoint of the group $G_{r+2 k}$ has $2 k+1$ invariants, one of which is the invariant of the adjoint of the isomorphic group $G_{r}$, and by considering the different possible forms of these invariants he finds some of the corresponding structural constants.

\section{Dr. J. F. Ritt: Periodic functions with a multiplication theorem.}

Let $f(z)$ represent a uniform analytic function with no essential singularity in the finite part of the plane, and periodic, either simply or doubly. Dr. Ritt determines all cases in which a number $m$ exists such that $f(m z)$ is a rational function of $f(z)$. The results are practically negative. The modulus of $m$ cannot be less than unity. If $|m|>1$ and if $f(z)$ is simply periodic, $f(z)$ is a linear function of $e^{\alpha z}$ or of $\cos (\alpha z+\beta)$, where $\beta$ is restricted to certain values. If $|m|>1$ and if $f(z)$ is doubly periodic, $f(z)$ must be a linear function of $p(z+\beta)$, except in the lemniscatic and equianharmonic cases. In the lemniscatic case $f(z)$ may be a linear function of $p^{2}(z+\beta)$ and in the equianharmonic case it may be a linear function either of $p^{3}(z+\beta)$ or of $p^{\prime}(z+\beta)$. For $|m|=1$, there is a wider variety of possibilities. 
9. Dr. J. F. Ritt: Note on equal continuity.

This paper appears in the present number of this BuLLETIN.

10. Professor I. J. Schwatt: Expressions for the Bernoulli function of order $p$.

Eisenlohr, Schlömilch, Worpitzky and others have derived expressions for the Bernoulli function. But their methods assume expansions involving the Bernoulli numbers. The author obtains expressions for the Bernoulli function directly from its definition.

11. Professor I. J. Schwatt: The expansion of a continued product.

By means of certain principles of operation with series, the author obtains the expansion of $\Pi_{k=1}^{p} \sin k x$ and also of $\sum_{n=0}^{p} \sum_{k=1}^{n-1} \sin ^{t}(k \pi / n)$ and of similar summations of continued products.

12. Professor I. J. Schwatt: Method for the summation of a family of series.

A further extension of the case which the author treated in the Nouvelles Annales de Mathématiques, (4), vol. 16, May, 1916, pp. 203-209, is considered in this paper.

13. Professor I. J. Schwatt: Note on the evaluation of a definite integral.

The evaluation of a definite integral from its definition as a summation presents even for some of the simpler cases considerable difficulty. The integrals of expressions which the author is unable to reduce to differentials of known functions lead to series which he cannot sum. Some of the principles involved in the summation of series obtained during the process of evaluating the definite integrals considered in this paper are believed to be new.

14. Mr. John McDonnell: A property of the Pellian equation with some results derived from it.

This paper shows that if $(t, u)$ be any solution of the Pellian equation

then

$$
t^{2}-D u^{2}=1 \text {, }
$$

$$
t+u \sqrt{D}=(x \sqrt{M}+y \sqrt{N})^{2},
$$


where $(x, y)$ is a solution of one of the equations $M x^{2}-N y^{2}$ $=1$ or $M x^{2}-N y^{2}=2$, and $M N=D$, where either $M$ or $N$ may be unity. From this result certain conclusions are drawn regarding the fundamental solution of the Pellian equation. It is shown as a further consequence that certain theorems on prime numbers established by Lucas in 1878 may be stated with greater precision, and the criteria derived from them rendered more definite.

15. Miss Anna M. Mullikin (introduced by Professor R. L. Moore): A necessary and sufficient condition that the sum of two bounded, closed and connected point sets should disconnect the plane.

The author shows that if, in a space $S$ of two dimensions, $m$ and $n$ are two bounded, closed, and connected point sets, neither of which separates $S$, then (1) in order that the point set $m+n$ should separate $S$ into at least two parts, it is necessary and sufficient that the set of points common to $m$ and $n$ should not be connected, (2) in order that $m+n$ should separate $S$ into just two connected domains it is sufficient that the set of points common to $m$ and $n$ should be the sum of two closed connected point sets that have no point in common.

16. Dr. T. H. Gronwall: Some empirical formulas in ballistics.

The author deduces approximate formulas for the range variations due to a change in temperature and to the rotation of the earth in terms of the variations due to changes in initial velocity, angle of departure and ballistic coefficient, thus making it possible to obtain all the differential variations in range by simple processes of interpolation from the ballistic tables devised by Professor Bennett and now being computed under his direction.

17. Dr. T. H. Gronwall: Summation of a double series.

In this paper, it is shown, by the use of Cauchy's theorem, that the double series

$$
\sum_{m, n=1}^{\infty} \frac{(m+n-2) !(m+n-1) !}{m !(m-1) ! n !(n-1) !} x^{2 m} y^{2 n}
$$

which was encountered by Dr. K. W. Lamson in the solution 
of a question in mathematical physics, has the sum

$$
\begin{aligned}
\frac{1}{2}[1- & x^{2}-y^{2} \\
& -\sqrt{(1+x+y)(1+x-y)(1-x+y)(1-x-y)}],
\end{aligned}
$$

the domain of convergence being $|x|+|y|<1$.

18. Professor L. P. Eisenhart: A geometric characterization of the paths of particles in the gravitational field of a mass at rest.

Schwarzschild integrated the differential equations of a permanent gravitational field in the Einstein theory and obtained the quadratic form

$$
d s^{2}=\left(1-\frac{2 m}{r}\right) d t^{2}+\frac{r}{2 m-r} d r^{2}-r^{2}\left(d \theta^{2}+\sin ^{2} \theta d \varphi^{2}\right) .
$$

The geodesics of the four-space with this linear element are the paths of a particle moving in the gravitational field produced by a mass $m$ at rest at the point $r=0$. It can be shown that these geodesics can be identified with the geodesics of a three-space $\Sigma$ with the linear element

$$
d s^{2}=\left(1-\frac{2 m}{r}\right) d t^{2}+\frac{r}{2 m-r} d r^{2}-r^{2} d \theta^{2} .
$$

The author has shown that $\Sigma$ is characterized by the following properties: (i) it admits a continuous group $G_{2}$ of motions into itself; (ii) the $\infty^{1}$ surfaces $S_{1}$ of $\Sigma$ which move into themselves for each motion of the group form part of a triply orthogonal system; (iii) the directions of the curves of intersection of the surfaces, $S_{1}, S_{2}, S_{3}$, of the triple system through a point $P$ are the principal directions of $\Sigma$ at $P$, in the sense that one of the surfaces, $S_{1}, S_{2}, S_{3}$, through $P$ has the maximum gaussian curvature and another the minimum curvature at $P$ of all the surfaces of $\Sigma$ through $P$; (iv) the curvature of $S_{1}$ is different from zero and equal to the curvature of $S_{2}$ or $S_{3}$, and the curvature of the other is minus twice that of $S_{1}$. This paper will appear in the AnNals of Mathematics.

19. Professor A. A. Bennett: The equations of interior ballistics.

In this paper, the derivation and interpretation of a set of three fundamental equations for interior ballistics are dis- 
cussed. These equations are in approximately the usual form, except for a change of variables. This change of variables is necessitated if tables are to be constructed to give all of the data desired for interior ballistics. The equations have been integrated numerically in the office of the Technical Staff of the Ordnance Department, and tables have been constructed which will shortly be published as a Government Document. The novelty of the undertaking consists in the introduction for the first time of new standard variables, which have a fundamental physical significance. The tables secured are independent of physical dimensions and appear to be the first to be published which correspond directly to the equations in their classical form. The results from the tables must be multiplied by external factors which involve the physical dimensions and depend upon the units chosen.

\section{R. G. D. Richardson,} Secretary.

\section{NOTE ON EQUAL CONTINUITY.}

BY DR. J. F. RITT.

(Read before the American Mathematical Society February 26, 1921.)

The notion of equal continuity, introduced by Ascoli, has acquired prominence through applications made of it by Hilbert, Montel and others.* A family of functions, defined on an interval, is equally continuous at a point if for every positive number there is an interval containing the point, in which the oscillation of each of the functions is less than the number.

Dealing with families of functions which are not equally continuous, we shall record here some properties of a function which will be called the saltus of the family.

Choosing a point on the interval of definition of the functions, let us suppose that there exists a number for which an interval can be found, containing the point, in which the oscillation of each of the functions is less than the number.

* For the literature on this question, see Montel, Sur les suites infinies de fonctions, ANNALES DE L'ECOLE NORMALE, 1907. 